\title{
Low Frequency Hearing Loss
}

National Cancer Institute

\section{Source}

National Cancer Institute. Low Frequency Hearing Loss. NCI Thesaurus. Code C35583.

Sensorineural hearing loss in which a person loses the ability to hear sounds in low frequency. 